\title{
INFLUENCIA DE DIFERENTES SISTEMAS DE MANEJO E CALAGEM EM EXPERIMENTO DE LONGA DURAÇÃO SOBRE FUNGOS MICORRÍZICOS ARBUSCULARES ${ }^{1}$
}

\author{
Influence of different management systems and liming on mycorrhizal \\ arbuscular fungi in a long-term experiment ${ }^{1}$
}

\author{
Jerusa Schneider ${ }^{2}$, Osmar Klauberg Filho ${ }^{3}$, Sandra Mara Vieira Fontoura ${ }^{4}$, Mauricio Vicente Alves ${ }^{2}$
}

\begin{abstract}
RESUMO
Visando estudar a influência de diferentes sistemas de manejo do solo com e sem calagem, sobre a colonização micorrízica radicular e a produção de micélio extrarradicular, por meio de técnica de análise multivariada, utilizou-se um experimento implantado em 1978, no município de Guarapuava, PR. A análise de componentes principais comprovou a existência de efeitos negativos do sistema de preparo convencional do solo sobre a colonização de fungos micorrízicos arbusculares (FMAs) do solo, principalmente em estruturas como arbúsculos e vesículas. A calagem apresentou benefícios para os parâmetros de colonização micorrízica e comprimento de micélio extrarradicular, sendo mais significativo nos sistemas de manejo conservacionistas, principalmente o sistema de plantio direto. Nas áreas de sistemas convencionais ocorreu uma redução na colonização micorrízica e, conseqüentemente, diminuição dos efeitos benéficos dos FMAs para as plantas, reduzindo a qualidade do solo e a sustentabilidade.
\end{abstract}

Termos para indexação: Plantio direto, colonização micorrízica, micélio extrarradicular, análise multivariada, ACP.

\section{ABSTRACT}

The objective of this work was to evaluate the influence of different soil management systems with and without liming on root colonization and production of extraradicular mycelium. Through multivariate analysis technique, an experiment established in 1978 in Guarapuava, state of Paraná was used. Correspondence analysis proved the existence of negative effects of the conventional tillage on the root mycorrhizal colonization (AMF) of the soil, mainly in structures as arbuscules and vesicles. The liming showed to be beneficial for the parameters of root micorrhyzal colonization and hyphal length, being more significant for conservationist management systems, such as no-tillage. In the areas under conventional management systems there was a reduction in micorrhyzal root colonization and consequently a decrease in beneficial effects of AMF for the plants, reducing the quality of the soil and the sustainability.

Index terms: No-tillage, mycorrhizal colonization, extraradicular mycelium, multivariate analysis, PCA.

(Recebido em 11 de março de 2008 e aprovado em 28 de julho de 2010)

\section{INTRODUÇÃO}

A adoção de sistemas conservacionistas de manejo do solo como plantio direto tem-se apresentado como uma alternativa para contribuir com a sustentabilidade econômica e ambiental do agroecossistema. No sistema de plantio direto (PD), a permanência dos resíduos vegetais na superfície do solo promove menores impactos nas propriedades do solo, maior disponibilidade de nutrientes e melhores condições para a atividade microbiana (SILVA et al., 2000).

Os fungos micorrízicos arbusculares (FMAs) representam um dos principais componentes da microbiota do solo na maioria dos agroecosistemas. Esses simbiontes mutualistas obrigatórios pertencentes ao filo Glomeromycota (MOREIRA; SIQUEIRA, 2006) tornam-se de extrema importância na maximização do uso de nutrientes, como o fósforo $(\mathrm{P})$, cobre $(\mathrm{Cu})$ e zinco $(\mathrm{Zn})$, e as hifas extrarradiculares desempenham um papel fundamental na formação de agregados (KABIR, 2005) por meio da exsudação de glomalina, uma glicoproteína cuja função é cimentar as partículas do solo

Os FMAs certamente atuam como importantes contribuintes na melhora de qualidade do solo observada no PD. Nesse sistema, além do não revolvimento do solo, as rotações de cultura, vegetação de cobertura e reduções na fertilização mineral podem atuar diretamente sobre a esporulações e a rede de micélio de FMAs no solo, como também indiretamente, via planta, sobre a colonização micorrízica e a diversidade de espécies (CASTILHO et al., 2006).

Sistemas de manejo do solo que reduzam a colonização micorrízica das culturas podem ter consequências drásticas a médio e longo prazo para a sua produção e sustentabilidade (ALGUACIL et al., 2008).

${ }^{1}$ Parte da Tese de Mestrado do primeiro autor apresentada à Universidade do Estado de Santa Catarina/UDESC

2Universidade Federal de Lavras/UFLA - Departamento de Ciência do Solo/DCS - Cx. P. 3037 - 37200-000 - Lavras, MG - jerusaschneider@gmail.com ${ }^{3}$ Universidade do Estado de Santa Catarina/UDESC - Centro de Ciências Agroveterinárias/CAV - Departamento de Solos - Lages, SC ${ }^{4}$ Fundação Agrária de Pesquisa Agropecuária/FAPA - Guarapuava, PA 
Portanto, considerando a grande extensão de terras agricultáveis do Brasil, as condições climáticas e a ocorrência de solos de baixa fertilidade natural (MACIEL et al., 2009), torna-se de grande importância avaliar a influência dos diferentes sistemas de manejo do solo sobre os FMAs, podendo a presença dessa associação ainda servir como indicador de qualidade do solo e sustentabilidade do sistema.

Neste estudo, objetivou-se avaliar o efeito de diferentes sistemas de manejo do solo com e sem calagem em um Latossolo Bruno alumínico, sobre a colonização micorrízica radicular e a produção de micélio extrarradicular nas culturas da soja [Glycine max (L.) Merr.] e consórcio ervilhaca (Vicia sativa L.) e nabo forrageiro (Raphanus sativus L.).

\section{MATERIAL E MÉTODOS}

\section{Localização e caracterização edafoclimática}

O estudo foi desenvolvido na região Centro-Sul do PR, o qual foi realizado em área experimental da
Fundação Agrária de Pesquisa Agropecuária - FAPA, no município de Entre Rios (PR). A área de estudo apresenta um Latossolo Bruno alumínico câmbico, com horizonte A proeminente (EMBRAPA, 1999), baixa saturação por bases e alto teor de Al trocável e a classificação climática predominante, segundo koppen, é Cfb. A região apresenta uma precipitação pluvial anual de 1600 a $2000 \mathrm{~mm}$, com boa ocorrência de chuvas na primavera-verão, apresentando média mensal de $178 \mathrm{~mm}$ entre os meses de outubro-março, com a ocorrência de chuvas semanalmente e com baixa frequência de ocorrência de verânicos. A temperatura média mensal oscila entre 12,5 (julho) e $20,5^{\circ} \mathrm{C}$ (janeiro), sendo a temperatura média anual de $16,8^{\circ} \mathrm{C}$ e a altitude entre 550 e $1100 \mathrm{~m}$. (SIMEPAR, 2006).

\section{Histórico da área experimental e amostragem}

O histórico e a descrição da área experimental encontram-se na Tabela 1.

Tabela 1 - Histórico e descrição das áreas experimentais (tratamentos).

\begin{tabular}{|c|c|}
\hline Período & Descrição das areas experimentais \\
\hline Originalmente & $\begin{array}{l}\text { Área era coberta por mata nativa, derrubada, em 1920, para formação de pastagem } \\
\text { composta por espécies nativas, principalmente gramíneas }\end{array}$ \\
\hline 1950 & $\begin{array}{l}\text { Solo foi arado pela primeira vez para o cultivo de trigo e arroz até 1962, quando foi } \\
\text { introduzida pastagem melhorada com trevo branco (Trifolium repens L.) e } \\
\text { gramíneas de inverno para gado leiteiro }\end{array}$ \\
\hline 1968 a 1977 & Cultivo de trigo/soja (Triticum aestivum L. e Glicine max) em preparo convencional \\
\hline \multirow[b]{2}{*}{1978} & 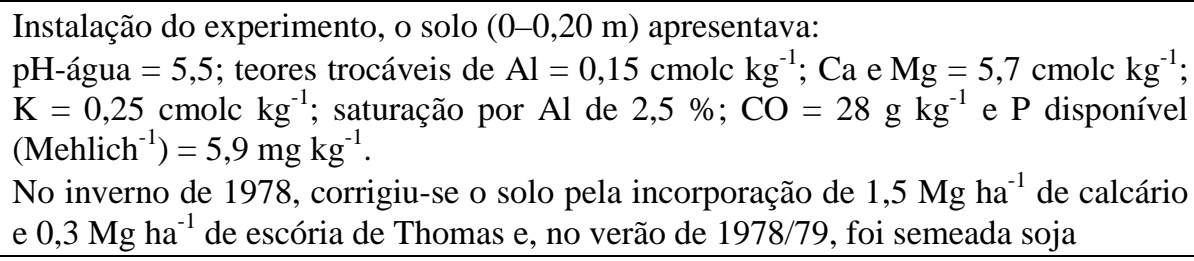 \\
\hline & $\begin{array}{l}\text { O experimento instalado consistiu, originalmente, em cinco combinações dos } \\
\text { sistemas de preparo convencional (PC), escarificação (ESC) e plantio direto (PD), } \\
\text { combinados no inverno e no verão (PC no inverno e no verão - PC; PC no inverno e } \\
\text { PD no verão - PC-PD; PD no inverno e PC no verão - PD-PC; PD no inverno e no } \\
\text { verão - PD; escarificado no inverno e plantio direto no verão - ESC-PD), aplicados } \\
\text { em parcelas de } 12 \text { x } 100 \text { m distribuídas em campo segundo o delineamento de blocos } \\
\text { ao acaso, com três repetições }\end{array}$ \\
\hline 1987 & $\begin{array}{l}\text { Introduziu-se no experimento o fator calagem em subparcelas de } 12 \text { × } 30 \mathrm{~m} \text {, } \\
\text { aplicando-se } 4,5 \mathrm{Mg} \mathrm{ha}^{-1} \text { de calcário calcítico. }\end{array}$ \\
\hline 1995 & Em maio de 1995, foram reaplicados $3 \mathrm{Mg} \mathrm{ha}^{-1}$ de calcário dolomítico. \\
\hline 1996 a 2001 & $\begin{array}{l}\text { Utilizou-se rotação de culturas com aveia branca (Avena sativa L.), trigo (Triticun } \\
\text { aestivum), cevada (Hordeum vulgare L.), ervilhaca comum (Vicia sativa), nabo } \\
\text { forrageiro (Raphanus sativus), soja (Glicine max) e milho (Zea mays L.). }\end{array}$ \\
\hline
\end{tabular}

Fonte: modificado de Ciotta et al. (2002).

Ciênc. agrotec., Lavras, v. 35, n. 4, p. 701-709, jul./ago., 2011 
O presente estudo foi realizado no ano de 2006, após 28 anos de instalação do experimento. Amostragens do solo foram realizadas nos meses de janeiro e agosto, cujos cultivos eram de soja e consórcio ervilhaca e nabo forrageiro, respectivamente. Todas as culturas receberam adubação NPK, exceto a ervilhaca que foi utilizada como fonte de $\mathrm{N}$ para o milho cultivado em sucessão. A dose de adubo aplicada foi de: $200 \mathrm{Kg} \mathrm{ha}^{-1}$ da fórmula 2-30-20 para a soja, e; $350 \mathrm{~kg} \mathrm{ha}^{-1}$ da fórmula 8-30-20 e $50 \mathrm{~kg} \mathrm{ha}^{-1} \mathrm{de} \mathrm{N} \mathrm{em}$ cobertura para o milho. A rotação de culturas foi a mesma em todos os sistemas de preparo do solo, e as operações de aplicação de defensivos e colheita foram realizadas com equipamentos utilizados em lavouras comerciais, obedecendo aos mesmos critérios técnicos destas. O manejo das plantas de cobertura foi feito por dessecação com herbicidas.

Três sistemas de manejo do solo sem aplicação de calcário e três com calcário incorporado foram escolhidos para avaliar a taxa de colonização micorrízica arbuscular (CMA) e comprimento de micélio extrarradicular total (CMET): 1) Plantio direto sem calcário (PD sem); 2) Plantio direto com calcário incorporado (PD inc); 3) Preparo reduzido sem calcário (PR sem); 4) Preparo reduzido com calcário incorporado (PR inc); 5) Preparo convencional sem calcário (PC sem); 6) Preparo convencional com calcário incorporado ( $\mathrm{PC}$ inc). $\mathrm{O}$ experimento foi constituído de blocos ao acaso, com esquema fatorial $3 \times 2 \times 2$. As parcelas foram constituídas pela combinação dos fatores: sistemas de manejo do solo, métodos de calagem e época de coleta das amostras.

Para a avaliação do efeito dos sistemas de manejo e calagem do solo sobre o comprimento de micélio extrarradicular (CMET), efetuou-se amostragem do solo em janeiro e agosto de 2006, cujos cultivos eram de soja e consórcio ervilhaca e nabo forrageiro, respectivamente. Foi coletada uma amostra composta por cinco subamostras em cada parcela, na profundidade de 0 a $10 \mathrm{~cm}$. As amostras foram armazenadas em sacos plásticos, acondicionadas em caixas térmicas com gelo e transportadas para o laboratório de Microbiologia do Solo, do Centro de Ciências Agroveterinárias (CAV), Universidade do Estado de Santa Catarina (UDESC), em Lages (Santa Catarina), onde foram mantidas em geladeira a $4^{\circ} \mathrm{C}$ até serem analisadas.

Para avaliação da colonização micorrízica (CMA) a campo, dez plantas de soja e ervilhaca foram coletadas ao acaso em cada parcela. No laboratório, as raízes foram lavadas e destacadas da parte aérea para posterior determinação da colonização micorrízica.

\section{Parâmetros analisados}

A taxa de colonização micorrízica (CMA) foi avaliada pela presença ou ausência de colonização em 120 segmentos de raízes, com aproximadamente $1 \mathrm{~cm}$ de comprimento, montados em lâminas para microscopia, conforme McGonigle et al. (1990). Esses segmentos foram selecionados ao acaso, de amostras de raízes clarificadas em $\mathrm{KOH}$ e coradas com azul de tripan 0,05\% (KOSKE; GEMMA, 1989). Com a determinação da taxa CMA verificou a presença ou ausência das demais estruturas de colonização, como hifas, vesículas e arbusculos, obtendo-se o percentual de cada parâmetro de colonização (Figura 1).

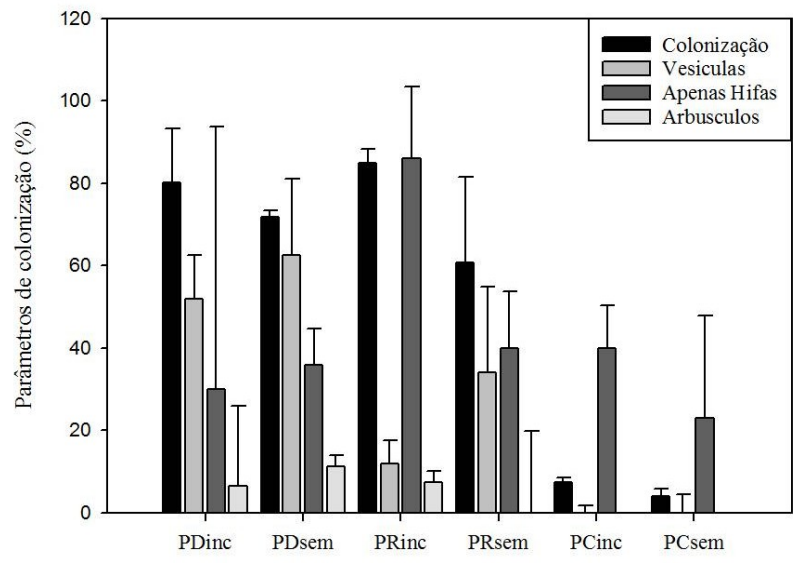

Figura 1 - Colonização micorrízica total nos diferentes sistemas de manejo (PD: plantio direto; PR: preparo reduzido; PC: preparo convencional) e aplicação de calcário (inc: incorporada; sem: sem calcário) Guarapuava, PR, 2006. Médias de 2 épocas e 3 repetições.

A quantificação do comprimento de micélio extrarradicular total no solo (CMET) foi feita por peneiramento úmido e filtração em membranas de celulose quadriculadas, segundo metodologia proposta por Melloni e Cardoso (1999).

Uma subamostra foi retirada das amostras de solo, e secas ao ar para a determinação dos seguintes atributos químicos: pH-SMP, pH-H O; P (Fósforo); K (Potássio); $\mathrm{Al}$ (Alumínio); Ca (Cálcio); Mg (Magnésio) e COT (Carbono orgânico total). Esses atributos químicos encontram-se apresentados na Tabela 2 .

\section{Análises estatísticas}

Os atributos de colonização micorrízica arbuscular (CMA) nos diferentes sistemas de manejo e calagem do 
Tabela 2 - Características químicas, colonização micorrízica e comprimento de micélio extra-radicular total no solo determinadas em amostras coletadas na camada de 0-10 cm de profundidade, em seis sistemas de manejo do solo. Guarapuava, PR, 2006. Médias de 3 repetições.

\begin{tabular}{|c|c|c|c|c|c|c|c|c|c|c|}
\hline \multirow{3}{*}{ Trat. } & \multicolumn{8}{|c|}{ Janeiro de 2006} & \multirow{3}{*}{$\begin{array}{c}\text { CMA } \\
----\%----\end{array}$} & \multirow{3}{*}{$\begin{array}{r}\text { CMET } \\
--\mathrm{cm} \mathrm{g}^{-1}--\end{array}$} \\
\hline & \multicolumn{2}{|c|}{$\mathrm{pH}$} & \multirow{2}{*}{\multicolumn{2}{|c|}{$\begin{array}{c}\mathrm{P} \\
--\mathrm{mg} \mathrm{dm}^{-3}--\end{array}$}} & $\mathrm{Al}$ & $\mathrm{Ca}$ & $\mathrm{Mg}$ & \multirow{2}{*}{$\begin{array}{c}\text { COT } \\
-\mathrm{g} \mathrm{kg}^{-1}-\end{array}$} & & \\
\hline & $\mathrm{H}_{2} \mathrm{O}$ & SMP & & & \multicolumn{2}{|c|}{$-----\mathrm{cmol}_{\mathrm{c}} \mathrm{dm}^{-3}$} & 1vig & & & \\
\hline $\mathrm{PD}^{1}$ inc $^{4}$ & 5,66 & 6,02 & 9,6 & 29 & 0,63 & 3,98 & 1,04 & 39,61 & 90,6 & 12,3 \\
\hline PD sem ${ }^{5}$ & 5,24 & 5,49 & 6,0 & 36 & 1,34 & 2,38 & 0,77 & 39,18 & 71,4 & 27,5 \\
\hline $\mathrm{PR}^{2}$ inc & 5,99 & 6,18 & 5,2 & 34 & 0,34 & 3,52 & 0,86 & 38,09 & 78,1 & 16,6 \\
\hline PR sem & 5,51 & 5,62 & 6,5 & 58 & 1,01 & 1,92 & 0,58 & 37,16 & 21,0 & 13,9 \\
\hline $\mathrm{PC}^{3}$ inc & 5,79 & 6,29 & 4,8 & 79 & 0,69 & 2,94 & 0,79 & 19,34 & 9,3 & 7,9 \\
\hline \multirow[t]{2}{*}{ PC sem } & 5,55 & 5,95 & 4,0 & 29 & 1,01 & 1,77 & 0,46 & 18,00 & 4,3 & 6,5 \\
\hline & \multicolumn{8}{|c|}{ Agosto de 2006} & & \\
\hline $\mathrm{PD}^{1}$ inc $^{4}$ & 5,40 & 5,61 & 6,4 & 44 & 0,70 & 2,62 & 0,79 & 33,61 & 80,3 & 10,2 \\
\hline PD sem ${ }^{5}$ & 5,02 & 5,20 & 5,6 & 44 & 2,44 & 1,34 & 0,47 & 26,69 & 60,4 & 24,2 \\
\hline $\mathrm{PR}^{2}$ inc & 5,71 & 5,82 & 5,2 & 66 & 0,35 & 2,94 & 0,94 & 25,71 & 21,7 & 15,7 \\
\hline PR sem & 5,17 & 5,23 & 6,5 & 52 & 2,04 & 1,21 & 0,38 & 23,49 & 58,2 & 12,3 \\
\hline $\mathrm{PC}^{3}$ inc & 5,64 & 5,81 & 4,3 & 74 & 0,36 & 2,39 & 0,69 & 19,34 & 7,3 & 5,4 \\
\hline PC sem & 5,33 & 5,62 & 3,8 & 78 & 1,71 & 1,27 & 0,33 & 18,00 & 3,3 & 2,1 \\
\hline
\end{tabular}

1PD: plantio direto; ${ }^{2} \mathrm{PR}$ : preparo reduzido; ${ }^{3} \mathrm{PC}$ : preparo convencional; ${ }^{4}$ inc: calcário incorporado; ${ }^{5}$ sem: sem calagem; CMA: Colonização micorrízica total; CMET: Comprimento micelial extra radicular total.

solo foram submetidos à analise de variância ANOVA, por meio do programa $\mathrm{SAS}^{\circledR}$; em seguida, os dados foram submetidos à Análise de Componentes Principais (ACP), usando o programa CANOCO versão 4.0, onde os mesmos foram transformados utilizando a formula de $\log (\mathrm{x}+1)$. Os atributos de CMA (Colonização Total, por hifas, vesículas, arbúsculos) e o CMET foram utilizados na separação das áreas, e os atributos químicos (pH-SMP, $\mathrm{pH}-\mathrm{H}_{2} \mathrm{O}, \mathrm{P}, \mathrm{K}, \mathrm{Al}, \mathrm{Ca}, \mathrm{Mg}$ e COT) foram utilizados posteriormente na ACP como variáveis explicativas das modificações nos sistemas de preparo do solo, com ou sem calagem. Os valores médios dos componentes principais padronizados das áreas estudadas foram comparados por meio do teste LSD $(\mathrm{p}<0,01)$, por meio do programa estatístico SAS ${ }^{\circledR}$ Learning Edition 2.0, conforme sugestão de Cruz-Castillo et al. (1994).

\section{RESULTADOS E DISCUSSÃO}

Os resultados encontrados após ACP demonstraram que, por meio da relação entre a componente principal 1 ( $\left.\mathrm{PCA}_{1}\right)$ e a componente principal 2 ( $\left.\mathrm{PCA}_{2}\right)$, houve separação entre os sistemas de manejo e a aplicação de calcário no solo. Essa variabilidade dos dados encontrada na primeira coleta, com a cultura da soja, foi explicada em $61,5 \%$ pela $\mathrm{PCA}_{1}$ e $27,2 \%$ pela
$\mathrm{PCA}_{2}$, totalizando $88,7 \%$ da variabilidade total dos dados (Figura 2).

A $\mathrm{PCA}_{1}$ separou claramente os sistemas convencionais dos demais (Figura 2), sendo o PCinc apresentou colonização micorrízica baixa, porém com a presença de hifas (Figura 1), com um valor padronizado expresso em módulo de $|1,1285|$ (Tabela 3). Alguns estudos demonstram os efeitos negativos do preparo do solo nos FMAs, sugerindo que isso possa promover a redução no rendimento da cultura posterior ao revolvimento do solo (COLOZZI-FILHO et al., 1999, KABIR, 2005, SOUZAet al., 2010). O preparo do solo é o mais direto e drástico estresse cultural que incide sobre a formação das micorrizas. A retirada da vegetação que acarreta na quebra do fluxo de exsudados radiculares e na disponibilidade de fotoassimilados, afeta a população de FMAs (COLOZZI-FILHO et al., 1999; CASTILHO et al., 2006; ALGUACIL et al., 2008).

Goss e Varennes (2002), verificaram que o sistema de plantio direto e cultivo mínimo mostraram maiores valores de colonização, quando comparado ao cultivo convencional para a cultura de feijoeiro. Resultados semelhantes também foram relatados por Oliveira \& Sanders (1999), onde a porcentagem de colonização no sistema de PD se mostrou superior ao do cultivo mínimo. 


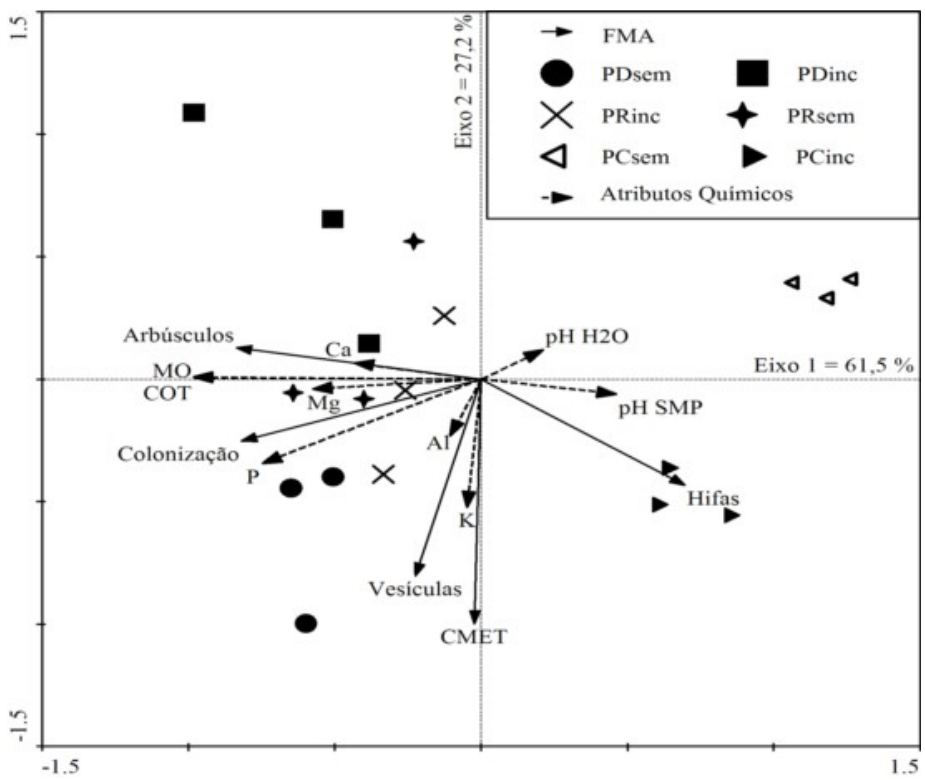

Figura 2 - Relação entre a componente principal 1 ( $\left.\mathrm{PCA}_{1}\right)$ e a componente principal $2\left(\mathrm{PCA}_{2}\right)$, discriminando sistemas de manejo do solo (PD: plantio direto; PR: preparo reduzido; PC: preparo convencional) e aplicação de calcário (inc: incorporado; sem: sem calcário) e as associações micorrízicas arbusculares (FMAs) e atributos químicos explicativos, na cultura de soja. Guarapuava, PR. Janeiro de 2006. CMET: Comprimento de micélio extra-radicular total do solo, pH: Potencial hidrogeniônico; MO: Matéria orgânica; COT: Carbono orgânico total do solo; Ca: Cálcio; Mg: Magnésio, P: Fósforo, K: Potássio; Al: alumínio.

Tabela 3 - Valores dos componentes principais no primeiro eixo $\left(\mathrm{PCA}_{1}\right)$ e segundo eixo $\left(\mathrm{PCA}_{2}\right)$, referentes à associação micorrízica arbuscular na cultura de soja, na região de Guarapuava, PR, janeiro de 2006. Primeira coleta, média de 3 repetições.

\begin{tabular}{ccc}
\hline FMAs $^{1}$ & $\mathrm{PCA}_{1}$ & $\mathrm{PCA}_{2}$ \\
\hline Colonização total & $-1,3263$ & -04084 \\
Hifas & 1,1285 & $-0,7007$ \\
Vesículas & $-0,3621$ & $-1,3002$ \\
Arbúsculos & $-1,3546$ & 0,2071 \\
CMET $^{2}$ & $-0,0364$ & $-1,6152$ \\
\hline
\end{tabular}

${ }^{1}$ FMAs: Fungos micorrízicos arbusculares; ${ }^{2} \mathrm{CMET}$ : comprimento de micélio extra-radicular total.

O sistema PDsem teve uma separação pela ACP pela colonização radicular total com um valor de $|1,3263| \mathrm{e}$ PRsem pelo atributo arbúsculo sendo esse com o maior valor $|1,3546|$ (Tabela 3). Para PCA $_{2}$ nota-se que esta separa os tratamentos PCsem do PCinc (Figura 2), sendo que este último teve uma maior influencia das hifas com um valor de |0,7007| (Tabela 3). Outra observação importante, é que essa componente também separa o PDinc do PDsem (Figura 2), com uma elevada presença de vesículas e CMET, apresentando |1,3002| e |1,6102|, respectivamente (Tabela 3).
Os atributos químicos auxiliaram na separação das áreas com 62,8\% sendo que COT e MO, seguido por P, auxiliaram no $\mathrm{PCA}_{1}$ com maior peso e $\mathrm{K}$ no $\mathrm{PCA}_{2}$ (Figura 2). Andrade et al. (1995), estudando a cultura do café, em Latossolo roxo, no Paraná, observaram que a colonização micorrízica aumentou com a adição de calcário, e comentam que os efeitos da calagem sobre a simbiose micorrízica não são claros porque, além de atuar diretamente sobre o fungo, a adição de calcário acarreta modificações químicas no solo que alteram o desenvolvimento da planta e da simbiose. 
No consórcio de ervilhaca e nabo forrageiro, novamente observou-se que houve uma separação entre os sistemas de manejo sendo explicada pelo PCA 1 com $58,1 \%$, este componente separa claramente os sistemas de PC independente da adição de calcário dos demais (Figura 3). O atributo que auxilia a separação desse sistema são as hifas, apresentando um valor de |0,9767| (Tabela 4). O PCA 2 explicou 23,0\% da variação total, e separa os tratamentos PD e PR sem calcário dos PD e PR com calcário (Figura 3), sendo os tratamentos sem calagem influenciados pela variável CMET, com um valor de $|1,1792|$ e os tratamentos com calcário incorporado pelas vesículas |1,8014| (Tabela 4).

Quando adicionou-se os atributos químicos à PCA, observou-se que as principais variáveis que auxiliaram o $\mathrm{PCA}_{1}$ foram $\mathrm{pH}$ em água e $\mathrm{K}$, seguido por $\mathrm{P}$, e no $\mathrm{PCA}_{2}$ foi Al seguido por Mg (Figura 2). A soma dos atributos químicos explicaram $72,3 \%$ da variação observada.

Observando-se a análise univariada sobre os componentes principais 1 e 2 na primeira coleta com a cultura de soja, confirmou-se a separação no eixo 1 dos sistemas conservacionistas em relação aos demais, demonstrando que o tratamento PC sem adição de calcário apresentou maior valor, ficando mais afastado dos demais, confirmando que esse sistema de manejo do solo é prejudicial à associação micorrízica. À medida que ocorre a adição de calcário no sistema PC, observa-se uma tendência de melhora do sistema, porém ainda sendo diferente estatisticamente dos sistemas conservacionistas (Tabela 5). O PCA demonstrou o efeito da calagem dentro dos sistemas, separando o PDinc do PCsem e o PDsem do PRinc (Tabela 5).

Para a segunda coleta, no consórcio de ervilhaca e nabo forrageiro, a análise univariada sobre à $\mathrm{PCA}_{1}$, demonstrou que os sistemas convencionais diferiram dos demais, e os sistemas PDinc e PRinc diferiram dos sistemas PDsem e PRsem. Observando o $\mathrm{PCA}_{2}$, somente os sistemas conservacionistas com calcário incorporado (PDinc e PRinc), diferiram estatisticamente pelo teste de LSD à $1 \%$ de significância dos demais sistemas (Tabela 6).

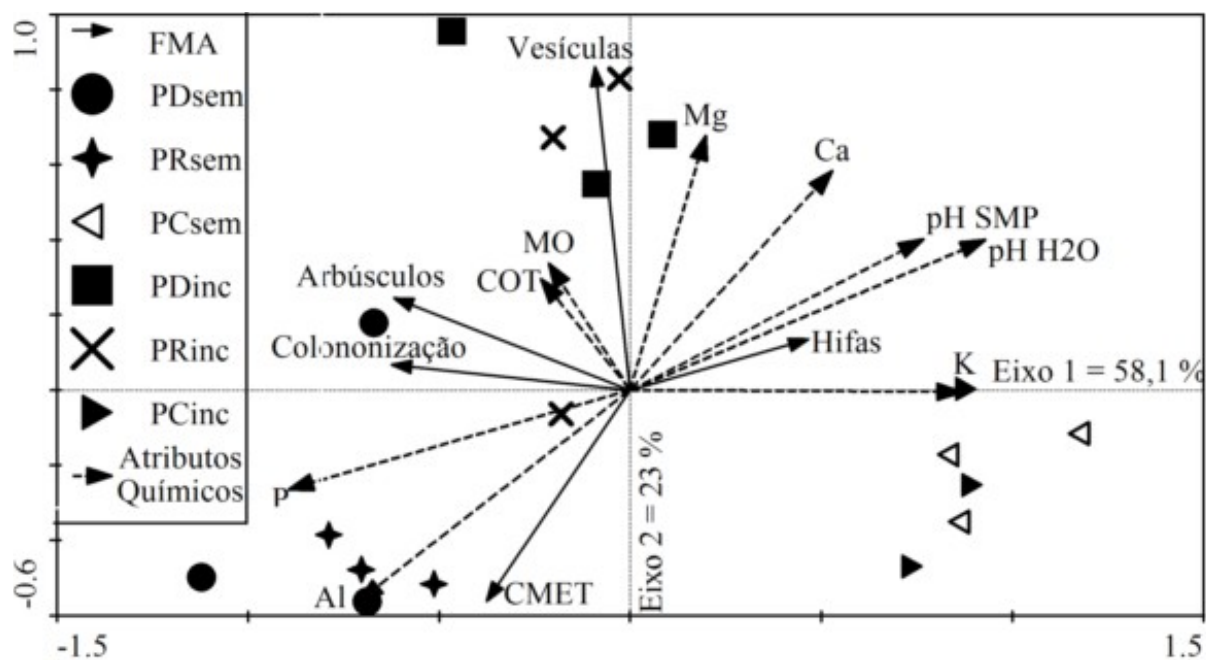

Figura 3 - Relação entre a componente principal 1 ( $\left.\mathrm{PCA}_{1}\right)$ e a componente principal 2 ( $\left.\mathrm{PCA}_{2}\right)$, discriminando sistemas de manejo do solo (PD: plantio direto; PR: preparo reduzido; PC: preparo convencional) e aplicação de calcário (inc: incorporada; sem: sem calcário) e as associações micorrízicas arbusculares (FMAs) e atributos químicos explicativos, na cultura de ervilhaca. Guarapuava, PR. Agosto 2006. CMET: Comprimento de micélio extra-radicular total do solo; $\mathrm{pH}$ : Potencial hidrogeniônico; MO: Matéria orgânica; COT: Carbono orgânico total do solo; Ca: Cálcio; Mg: Magnésio, P: Fósforo, K: Potássio; Al: alumínio. 
Tabela 4 - Valores dos componentes principais no primeiro eixo $\left(\mathrm{PCA}_{1}\right)$ e segundo eixo $\left(\mathrm{PCA}_{2}\right)$, referentes à associação micorrízica arbuscular na cultura de ervilhaca, na região de Guarapuava, PR, agosto de 2006. Segunda coleta, média de 3 repetições.

\begin{tabular}{ccc}
\hline FMAs $^{1}$ & $\mathrm{PCA}_{1}$ & $\mathrm{PCA}_{2}$ \\
\hline Colonização total & $-1,3263$ & -04084 \\
Hifas & 1,1285 & $-0,7007$ \\
Vesículas & $-0,3621$ & $-1,3002$ \\
Arbúsculos & $-1,3546$ & 0,2071 \\
CMET $^{2}$ & $-0,0364$ & $-1,6152$ \\
\hline
\end{tabular}

${ }^{1}$ FMAs: Fungos micorrízicos arbusculares; ${ }^{2} \mathrm{CMET}$ : comprimento de micélio extra-radicular total.

Tabela 5 - Teste de comparação de médias dos componentes principais padronizados, entre as associações micorrízicas arbusculares analisados no primeiro eixo $\left(\mathrm{PCA}_{1}\right)$ e no segundo eixo $\left(\mathrm{PCA}_{2}\right)$, na cultura de soja, nos diferentes sistemas de manejo e calagem do solo, na região de Guarapuava, PR, janeiro de 2006. Primeira coleta, média de 3 repetições.

\begin{tabular}{lcc}
\hline \multicolumn{1}{c}{ Tratamentos } & $\mathrm{PCA}_{1}$ & $\mathrm{PCA}_{2}$ \\
\hline Plantio Direto c/ calcário incorporado & $-0,6241 \mathrm{~d}$ & $0,6292 \mathrm{a}$ \\
Plantio Direto sem calagem & $-0,5849 \mathrm{~d}$ & $-0,6149 \mathrm{c}$ \\
Preparo Reduzido c/ calcário incorporado & $-0,2394 \mathrm{c}$ & $-0,0586 \mathrm{bc}$ \\
Preparo Reduzido sem calagem & $-0,4244 \mathrm{~cd}$ & $0,1421 \mathrm{ab}$ \\
Preparo Convencional c/ calcário incorporado & $0,6977 \mathrm{~b}$ & $-0,4734 \mathrm{c}$ \\
Preparo Convencional sem calagem & $1,1751 \mathrm{a}$ & $0,3779 \mathrm{ab}$ \\
\hline
\end{tabular}

Médias seguidas de letras iguais, na coluna, não diferem entre si pelo teste de $\operatorname{LSD}(\mathrm{p}<0,01)$.

Tabela 6 - Teste de comparação de médias dos componentes principais padronizados, entre as associações micorrízicas arbusculares analisados no primeiro eixo $\left(\mathrm{PCA}_{1}\right)$ e no segundo eixo $\left(\mathrm{PCA}_{2}\right)$, na cultura de ervilhaca, nos diferentes sistemas de manejo e calagem do solo, na região de Guarapuava, PR, agosto de 2006. Segunda coleta, média de 3 repetições.

\begin{tabular}{lcc}
\hline \multicolumn{1}{c}{ Tratamentos } & $\mathrm{PCA}_{1}$ & $\mathrm{PCA}_{2}$ \\
\hline Plantio Direto c/ calcário incorporado & $-0,1572 \mathrm{~b}$ & $0,7281 \mathrm{a}$ \\
Plantio Direto sem calagem & $-0,8275 \mathrm{c}$ & $-0,2942 \mathrm{~b}$ \\
Preparo Reduzido c/ calcário incorporado & $-0,1371 \mathrm{~b}$ & $0,4787 \mathrm{a}$ \\
Preparo Reduzido sem calagem & $-0,6688 \mathrm{c}$ & $-0,4599 \mathrm{~b}$ \\
Preparo Convencional c/ calcário incorporado & $0,8270 \mathrm{a}$ & $-0,2397 \mathrm{~b}$ \\
Preparo Convencional sem calagem & $0,9637 \mathrm{a}$ & $-0,2397 \mathrm{~b}$ \\
\hline
\end{tabular}

Médias seguidas de letras iguais, na coluna, não diferem entre si pelo teste de $\operatorname{LSD}(\mathrm{p}<0,01)$.

A colonização micorrízica e comprimento de micélio extrarradicular foram afetados pelo sistema de manejo do solo (Tabela 2 e Figura 1), como já relatado por diversos autores (COLOZZI-FILHO et al., 1999; OLIVEIRA; SANDERS, 1999; GOSS; VARENNES, 2002; KABIR, 2005; CASTILHO et al., 2006) onde sistemas convencionais de cultivo do solo promovem a quebra dos agregados e rompimento da rede de micélio, expondo os propágulos de FMA ao sol e à oxidação, o que pode inviabilizá-los e acarretar redução na colonização micorrízica. Nesse mesmo estudo, os propágulos de FMAs como esporos e raízes micorrizadas foram mais tolerantes as alterações no solo que as hifas. Embora as hifas extrarradiculares não 
estejam diretamente relacionadas como propágulos, a sobrevivência dos fungos no solo se relaciona com o volume de micélio viável produzido. As práticas de agricultura como a mecanização intensiva, uso de agroquímicos e variedades melhoradas podem reduzir a população de FMAs no solo (MOREIRA; SIQUEIRA, 2006), existindo efeitos negativos do sistema convencional de preparo do solo sobre os FMAs.

A combinação do cultivo mínimo com plantas com alto grau de micotrofia empregadas em cobertura contribuem para manter elevada densidade de hifas, elevado potencial de inoculo, estabilização do solo e, assim, manter a sustentabilidade da produção (KABIR, 2005). A adubação com doses excessivas de fertilizantes, uso indiscriminado de defensivos e o revolvimento intensivo do solo, são práticas que afetam negativamente os FMAs, e assim contribuem para a reduzida sustentabilidade de sistemas que empregam estas práticas (ALGUACIL et al., 2008).

\section{CONCLUSÕES}

Os sistemas de manejo do solo afetaram a colonização e a produção de micélio fúngico na cultura da soja e ervilhaca.

A análise de componentes principais demonstrou que o sistema de preparo convencional do solo reduziu a colonização de fungos micorrízicos arbusculares, principalmente a presença de arbúsculos e vesículas.

A calagem foi benéfica para os atributos de colonização micorrízica e comprimento de micélio extrarradicular, sendo mais significativa no plantio direto.

\section{AGRADECIMENTOS}

Os autores agradecem à CAPES e ao CNPq, pela bolsa de estudos; ao PAP/UDESC, pelo financiamento do projeto; e à Fundação Agrária de Pesquisa Agropecuária (FAPA) pela área experimental utilizada para execução desse trabalho.

\section{REFERÊNCIAS BIBLIOGRÁFICAS}

ALGUACIL, M.M. et al. The impacto g tillage practices on arbuscular mycorrhizal fungal diversity in subtropical crops. Ecological Applications, v.18, p.527536, 2008.

ANDRADE, D.S. et al. Atividade microbiana em função da calagem em um solo cultivado com cafeeiro. Revista Brasileira de Ciência do Solo, Campinas, v.19, p.191196, 1995.
CASTILHO, C.G. et al. Early effects of tillage and crop rotation on arbuscular mycorrhizal fungal propagules in an Ultisol. Biology and Fertility of Soils, v.43, p.83-92, 2006.

CIOTTA, M.N. et al. Acidificação de um latossolo sob plantio direto. Revista Brasileira de Ciência do Solo, Campinas, v.26, p.1055-1064, 2002.

COLOZZI-FILHO, A.; BALOTA, E.L.; ANDRADE, D.S. Microrganismos e processos biológicos no sistema plantio direto. In: SIQUEIRA, J.O.; et al. Inter-relação fertilidade, biologia do solo e nutrição de plantas. Viçosa, MG: Sociedade Brasileira de Ciência do Solo, 1999. p.487-508.

CRUZ-CASTILLO, J.G. et al. Applications of canonical discriminant analysis in horticultural research.

HortScience, Amsterdam, v.29, p.1115-1119, 1994.

\section{EMPRESA BRASILEIRA DE PESQUISA}

AGROPECUARIA-EMBRAPA. Centro Nacional de Pesquisas de Solos. Sistemas brasileiro de classificação de solo. Brasília: Embrapa, 1999. 412p.

GOSS, M.J.; VARENNES, A. Soil disturbance reduces the efficacy of mycorrhizal associations for early soybean growth and $\mathrm{N}_{2}$ fixation. Soil Biology Biochemistry, Oxford, v.34, n.8, p.1167-1173, 2002.

KABIR, Z. Tillage or no-tillage: impact on mycorrhizae. Canadian Journal of Plant Science, Ottawa, v.85, p.2329, 2005.

KOSKE, R.E.; GEMMA, J.N. A modified procedure for staining roots to detect VA mycorrhizas.

Mycological Research, Amsterdam, v.92, n.4, p.486488, 1989.

MACIEL, G. A.; FERREIRA, M. M.; EVANGELISTA, A. R.; OLIVEIRA, G. C. Relação de atributos físicos do solo e produtividade de pastagem em sub-bacias hidrográficas do município de Lavras-MG. Ciência e Agrotecnologia, v.33, p. 2025-2030, 2009.

MCGONIGLE, T.P.et al. A new method which gives an objective measure of colonization of roots by vesiculararbuscular mycorrhizal fungi. New Phytologist, Saint Paul, v.115, p.495-501, 1990. 
MELLONI, R.; CARDOSO, E.J.B.N. Quantificação de micélio extra-radicular de fungos micorrízicos arbusculares em plantas cítricas: II., comparação entre diferentes espécies cítricas e endófitos. Revista

Brasileira de Ciência do Solo, Campinas, v.23, p.59-67, 1999.

MOREIRA, F.M.S.; SIQUEIRA, J.O. Microbiologia e bioquímica do solo. 2.ed. Lavras: Editora UFLA, 2006. 729 p.

OLIVEIRA, A.A.R.; SANDERS, F.E.E. Effect of management practices on mycorrhizal infection. Pesquisa Agropecuária Brasileira, Brasília, v.34, n.7, p.1247-1254, 1999.
SILVA, V.R.; REINERT, D.J.; REICHERT, J.M. Densidade do solo, atributos químicos e sistema radicular do milho afetados pelo pastejo e manejo do solo. Revista Brasileira de Ciência do Solo, Campinas, v.24, p.191-199, 2000.

SIMEPAR. Instituto tecnológico SIMEPAR. Disponível em: <http:///www.simepar.br/tempo2/noticias/ index.shtml $>$. Acesso em: 13 nov. 2006.

SOUZA, F.R.; ROSA JUNIOR, E.J.; FIETZ, C.R.; BERGAMIN, A.C.; VENTUROSO, L.R.; ROSA, Y.B.C.J. Atributos físicos e desempenho agronômico da cultura da soja em um Latossolo Vermelho distroférrico submetido a dois sistemas de manejos. Ciência e Agrotecnologia, Lavras, v.34, n.6, p. 1357-1364. 2010. 